\title{
WIN55,212-2 induces cytoplasmic vacuolation in apoptosis-resistant MCL cells
}

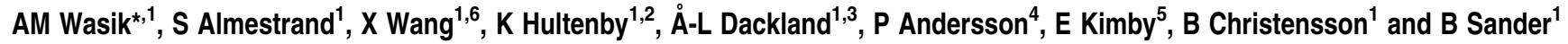

Cannabinoid receptors 1 (CB1) and/or 2 (CB2) are overexpressed in many types of human malignancies including mantle cell lymphoma (MCL). Agonists to $\mathrm{CB} 1$ and $\mathrm{CB} 2$ promote ceramide de novo synthesis, p38-mitogen-activated protein kinasedependent activation of caspase-3 and apoptotic cell death in most MCLs. However, in this report we describe that in some MCLs the response to treatment with cannabinoids decreased cell viability as assessed by metabolic activity but did not involve the caspase-3 cascade or loss of plasma membrane integrity. Both primary cells from one MCL patient and the MCL cell line Granta519 responded to treatment with cannabinoids by formation of cycloheximide-sensitive cytoplasmic vacuoles, but did not enter apoptosis. The persistent expression of mammalian homolog of Atg8 with microtubule-associated protein-1 light chain-3 II (LC3 II) and p62, as well as the lack of protection from chloroquine, indicates that lysosomal degradation is not involved in this cytoplasmic vacuolation process, distinguishing from classical autophagy. Transmission electron microscopy images and immunofluorescence staining of endoplasmic reticulum (ER) chaperone calreticulin showed that the vacuoles were of ER origin and that chromatin remained normal. These features resemble paraptosis-like cell death-a third type of a programmed cell death not previously described in response to cannabinoids.

Cell Death and Disease (2011) 2, e225; doi:10.1038/cddis.2011.106; published online 3 November 2011

Subject Category: Cancer

Mantle cell lymphoma $(\mathrm{MCL})$ is a non-Hodgkin lymphoma of B-cell type, with a median survival of 3-5 years. ${ }^{1}$ Improved treatment protocols have been presented, ${ }^{2,3}$ and patients below 65 years of age may benefit from intense treatment and autologous stem cell transplantation. However, the vast majority of patients cannot be rescued and new treatment options are clearly needed, therefore search for new therapy targets is ongoing.

Previously, we have found that MCL has high expression of the G-protein-coupled receptors, cannabinoid receptors type 1 (CB1) and type 2 (CB2). ${ }^{4,5}$ The high expression of CB1 on lymphoma cells was unexpected, as CB1 is expressed at very low levels in the immune system. ${ }^{6,7}$ CB2 is expressed on normal $B$ cells, but expression levels are even higher on the malignant $\mathrm{B}$ cells in MCL. ${ }^{4,5}$ CB2 may also be highly expressed in T-cell malignancies. ${ }^{8,9}$ In the immune system, CB2 regulates cell-mediated and humoral immunity ${ }^{10-12}$ and leukocyte migration. ${ }^{11,13-15}$

Initially, cannabinoids were used in palliative cancer therapy. Recently, it has been recognized that cannabinoids also have specific anti-tumor activity by inducing selective cell death in many types of cancer cells but not in the normal counterparts. ${ }^{16-18}$ Our earlier studies demonstrated that targeting $\mathrm{CB} 1$ and $\mathrm{CB} 2$ receptors on $\mathrm{MCL}$ cell lines and primary tumors cells with endocannabinoids or other agonists to cannabinoid receptors (methanandamide and WIN55, 212-2) selectively reduced proliferation and induced de novo synthesis of ceramides, followed by p38-mitogen-activated protein kinase (MAPK)-dependent apoptosis of lymphoma cells. ${ }^{19,20}$ Furthermore, the cannabinoid methanandamide reduced tumor growth in MCL in a xenograft mouse model. ${ }^{4}$ Intriguingly, high expression of cannabinoid receptors did not always result in caspase-3-mediated cell death in B-cell lymphomas treated with cannabinoids ${ }^{4}$ but still, as we show in the current study, decreased the mitochondrial activity. We therefore hypothesized that cannabinoids may induce other types of programmed cell death (PCD) than apoptosis (PCD I). Here, we show that cannabinoids may induce non-apoptotic PCD in MCL, widening their therapeutic potential.

\footnotetext{
${ }^{1}$ Division of Pathology, Department of Laboratory Medicine, F46, Karolinska Institutet, Karolinska University Hospital, Huddinge, SE 14186 Stockholm, Sweden; ${ }^{2}$ Clinical Research Center, Department of Laboratory Medicine, Karolinska University Hospital, Huddinge, SE 14186 Stockholm, Sweden; ${ }^{3}$ Center for Cell Analysis, Department of Laboratory Medicine, Karolinska Institutet, Karolinska University Hospital, Huddinge, SE 14186 Stockholm, Sweden; ${ }^{4}$ Department of Hematology, Stockholm South Hospital, SE 11883 Stockholm, Sweden and ${ }^{5}$ Division of Hematology, Department of Medicine, Karolinska Institutet, Karolinska University Hospital, Huddinge, SE 14186 Stockholm, Sweden

${ }^{*}$ Corresponding author: AM Wasik, Division of Pathology, Department of Laboratory Medicine, F46, Karolinska Institutet, Karolinska University Hospital, Huddinge, SE 14186 Stockholm, Sweden. Tel: + 4685858 1034; Fax: + 4685858 7730; E-mail: agata.wasik@ki.se

${ }^{6}$ Current address: Centre for Primary Healthcare Research, Lund University Hospital, SE 20502 Malmö, Sweden.

Keywords: cannabinoid; mantle cell lymphoma; programmed cell death

Abbreviations: CB1, cannabinoid receptor 1; CB2, cannabinoid receptor 2; CNR1, gene encoding cannabinoid receptor 1; CNR2, gene encoding cannabinoid receptor 2; MCL, mantle cell lymphoma; PCD, programmed cell death; PI, propidium iodide; IC50, half maximal inhibitory concentration; AEA, anandamide; PARP, poly (ADP-ribose) polymerase; LC3, mammalian homolog of Atg8 with microtubule-associated protein-1 light chain-3; ER, endoplasmic reticulum; CHOP, (CCAAT/enhancerbinding protein) homologous protein; BiP, binding immunoglobulin protein; UPR, unfolded protein response; IGF1R, insulin-like growth factor-1 receptor; EGF, epidermal growth factor; MAPK, mitogen-activated protein kinase; Bcl2, B-cell lymphoma 2; Bax, Bcl2-associated X protein; Bcl-x L, B-cell lymphoma-extra large; EBV, EpsteinBarr virus; EBER, EBV-encoded RNA; TEM, transmission electron microscopy; FBS, fetal bovine serum; $\mathrm{CHX}$, cycloheximide; $\mathrm{CQ}$, chloroquine

Received 28.2.11; revised 21.9.11; accepted 21.9.11; Edited by A Stephanou
} 


\section{Results}

Cannabinoid-mediated cell death of primary MCL cells and MCL cell lines. Primary MCL lymphoma cells were obtained from six patients. From two patients - PA and PB two different tissues were obtained. The expression levels of gene encoding cannabinoid receptor 1 (CNR1) and cannabinoid receptor 2 (CNR2) was determined by quantitative PCR (Table 1). The expression levels of the cannabinoid receptors were normalized to $B$ cells purified from a buffy coat from a healthy donor. The effect of the synthetic cannabinoid WIN55,212-2, a potent agonist to CB1 and $\mathrm{CB} 2$ receptors, on cell viability was assessed by two principally different methods. The integrity of the plasma cell membrane was analyzed by flow cytometry for the uptake of the DNA stain propidium iodide (PI), which cannot pass through intact cell membranes. In addition the XTT viability assay, which is based on detecting mitochondrial activity, was used for viability assessment. In five out of six primary MCLs, WIN55,212-2 induced a dose-dependent decreased cell viability, as assessed by flow cytometry, at $48 \mathrm{~h}$. Half maximal inhibitory concentration (IC50) values represent WIN55,212-2 concentrations at which the viability reaches $50 \%$. These values were varying between $\sim 1.5$ and $5 \mu \mathrm{M}$ for PA, PC, PD, PE and PF primary samples. Lymphoma cells isolated from blood or bone marrow from the patient $\mathrm{PB}$ (PB1 and PB2, respectively) were resistant to cannabinoidinduced PI uptake (Figure 1a). Using the same viability assay, the Granta519 cell line, but not other MCL cell lines tested (Rec1, JeKo and JVM2), showed a similar resistance to WIN55,212-2-induced PI uptake (Figure 1b). In contrast, using the XTT viability assay, no such difference between Granta519 and the other MCL cell lines was observed (Figure 1c). This discordance in viability assessment results might indicate that different modes of cannabinoid-mediated toxicity are operational.

Granta519 and PB1 cells are resistant to cannabinoidinduced apoptosis. We have further analyzed the possible role of caspase-3-dependent effector mechanism as a factor underlying the observed differences in cell death. The response of Granta519 was compared with the other MCL cell lines, Rec1, JeKo and JVM2 to incubation with
$10 \mu \mathrm{M}$ WIN55,212-2 (Figure $2 \mathrm{a}$ ) or $10 \mu \mathrm{M}$ anandamide (AEA, $\mathrm{N}$-arachidonoylethanolamine; Figure $2 \mathrm{~b}$ ). At $24 \mathrm{~h}$ after adding cannabinoids, all cell lines but Granta519 were dead. Kinetic studies for up to $10 \mathrm{~h}$, using western blot, showed that after $5 \mathrm{~h}$ cannabinoids had activated caspase- 3 and poly (ADP-ribose) polymerase (PARP) cleavage in Rec1, JeKo and JVM2 but not in Granta519 (Figures 2a and b). Similarly, PARP cleavage was not detected in PB1 cells after treatment with $10 \mu \mathrm{M}$ WIN55,212-2 (Figure 2c). These data indicate that Granta519 cells respond to cannabinoids by decreased metabolic activity, and together with PB1 cells are resistant to apoptosis.

Phase-contrast microscopy of Granta519 cell cultures for $48 \mathrm{~h}$ in the presence of $10 \mu \mathrm{M}$ WIN55,212-2 showed cytoplasmic vacuoles (Figure 3a). Vacuolation is a feature of autophagy, but can also be a feature of other processes such as paraptosis/cytoplasmic vacuolation. In autophagy, autophagosomes are formed, which finally fuse to lysosomes forming autolysosomes. The process also involves the conversion of mammalian homolog of Atg8 with microtubule-associated protein-1 light chain-3 I (LC3 I) to a PE-conjugated form, denoted LC3 II, which localizes in the autophagosomes. The formation of LC3 II is, however, not specific for autophagy but also occurs during cytoplasmic vacuolation. ${ }^{21}$ We investigated the changes in LC3 I and LC3 II expression levels in MCL cell lines up to $10 \mathrm{~h}$ of treatment with $10 \mu \mathrm{M}$ WIN55,212-2. During this time, we did not observe any enhanced expression of LC3 II in any of MCL cell lines investigated (Figures $2 a$ and $b$ ). However, after incubating Granta519 cells with $10 \mu \mathrm{M}$ WIN55,212-2 or AEA for 24 and $48 \mathrm{~h}$, LC3 II levels were elevated compared with vehicletreated cells (Figure $3 b$ ).

Cannabinoid-induced vacuolation does not involve lysosomal degradation and is insensitive to MEK-1 and -2 inhibitors. During autophagy, the protein p62 localizes in the autophagosomes and is, together with LC3 II, degraded in autolysosomes. Therefore, changes in levels of LC3 II and p62 proteins may reflect stages of the autophagy. ${ }^{22}$

To characterize the cannabinoid-induced LC3 II-positive vacuolation, cells were treated with WIN55,212-2 or AEA for 24 and $48 \mathrm{~h}$, and levels of the vacuolar membrane protein p62 22,23 were analyzed. Cannabinoid treatment induced

Table 1 Characteristics of primary samples from patients with MCL and the expression levels of CNR1 and CNR2 in primary MCL cells and in MCL cell lines

\begin{tabular}{|c|c|c|c|c|c|c|}
\hline Sample & Sex & $\begin{array}{c}\text { Age } \\
\text { (years) }\end{array}$ & Tissue & $\begin{array}{c}\text { Purity } \\
(\%)\end{array}$ & CNR1 & CNR2 \\
\hline PA1 & $\mathrm{M}$ & 82 & Blood & 86 & $11.25 \pm 1.12$ & $4.17 \pm 0.18$ \\
\hline PA2 & & & Pleural exudate & 95 & $10.83 \pm 1.08$ & $2.44 \pm 0.14$ \\
\hline PB1 & $F$ & 77 & Blood & 89 & $1.16 \pm 0.10$ & $2.54 \pm 0.26$ \\
\hline PB2 & & & Bone marrow & 92 & $6.15 \pm 0.77$ & $1.71 \pm 0.16$ \\
\hline$P C$ & $\mathrm{M}$ & 69 & Spleen & 80 & $1.54 \pm 0.09$ & $1.79 \pm 0.10$ \\
\hline PD & $\mathrm{M}$ & 73 & Spleen & 88 & $3.27 \pm 0.27$ & $1.28 \pm 0.02$ \\
\hline $\mathrm{PE}$ & $M$ & 77 & Lymph node & 85 & $2.33 \pm 0.22$ & $1.72 \pm 0.12$ \\
\hline $\mathrm{PF}$ & $M$ & 66 & Blood & 69 & $0.15 \pm 0.03$ & $1.17 \pm 0.25$ \\
\hline Granta519 & & & Blood & & $1.31 \pm 0.09$ & $0.31 \pm 0.05$ \\
\hline Rec1 & & & Lymph node or blood & & $2.24 \pm 0.52$ & $1.48 \pm 0.29$ \\
\hline JeKo & & & Blood & & $1.67 \pm 0.47$ & $1.33 \pm 0.21$ \\
\hline JVM2 & & & Blood & & $0.00 \pm 0.00$ & $0.02 \pm 0.00$ \\
\hline
\end{tabular}

The purity indicates the percentage of lymphoma cells among mononuclear cells evaluated by flow cytometry. The mRNA levels were measured using real-time PCR. The CNR1 and CNR2 mRNA levels were normalized to CNR1 and CNR2 mRNA levels in B cells from a buffy coat from a healthy donor, $n=9-12$ 


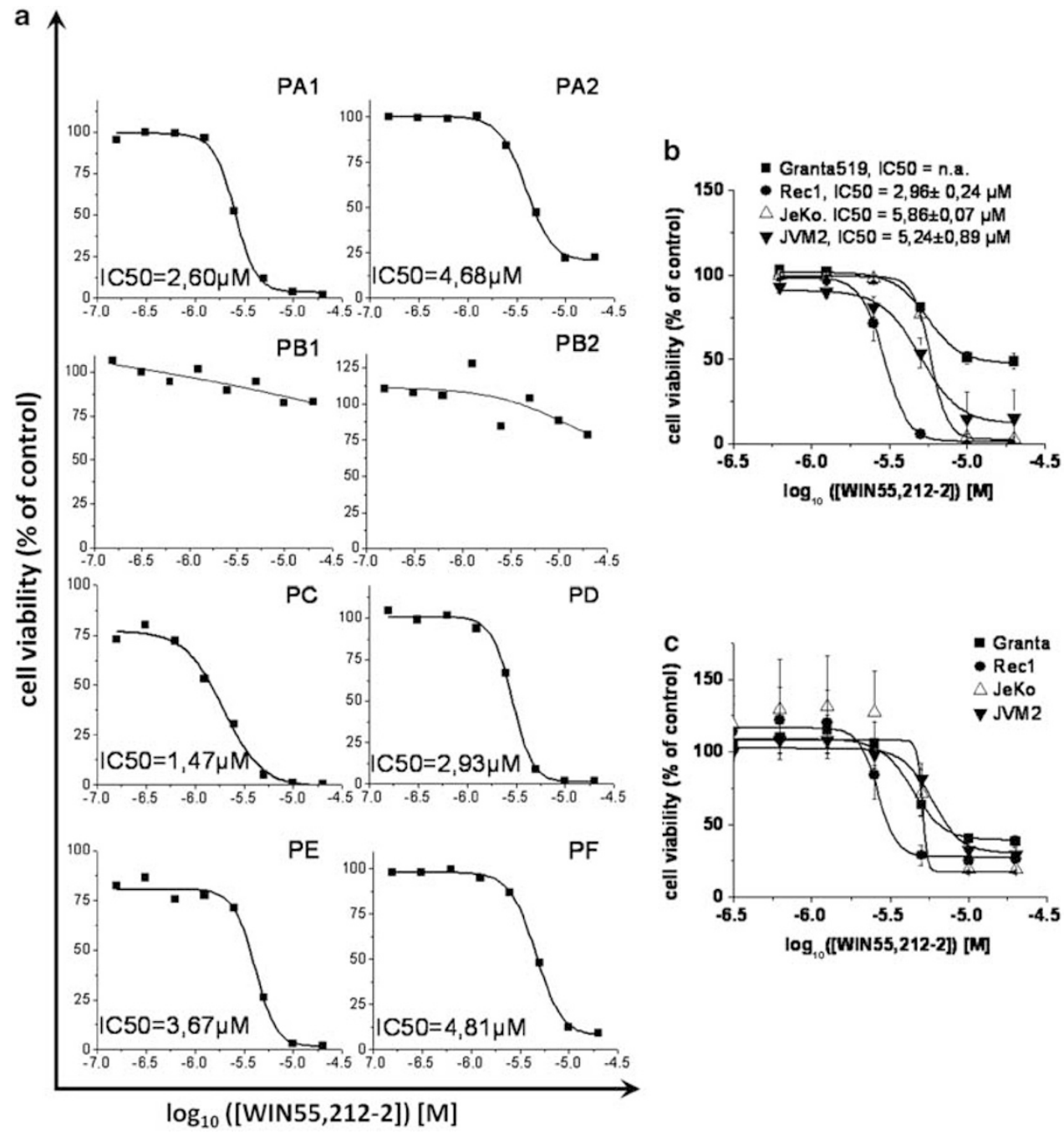

Figure 1 Primary MCL cells and cell lines respond differently to WIN55,212-2 treatment. Primary MCL cells (a) and MCL cell lines (b) were treated with WIN55,212-2. Cell viability was assessed by PI staining at $48 \mathrm{~h}$; the WIN55,212-2 concentration at which cell viability reaches $50 \%$ (IC50 values) are based on a four-parameter iterative fitting; (c) XTT assay $(n=3 \times 3)$ of MCL cell lines: Granta519, Rec1, JeKo and JVM2 treated with WIN55,212-2 for 48h

persistent expression of LC3 II and did not influence the levels of p62 (Figure 3b). The fact that LC3 II and p62 levels did not decrease over time suggests that vacuoles were not efficiently fused with the lysosomes. These findings suggest that the autophagocytic process was not completed, whereas the cellular metabolism, measured by XTT, was reduced as shown in Figure 1c.

To further analyze the vacuoles, we investigated whether changes in the lysosomal $\mathrm{pH}$ by chloroquine (CQ) treatment would influence the observed effect of cannabinoids. However, the cannabinoid-induced reduction of metabolism was not affected by $C Q$ treatment, indicating that lysosomal degradation was not involved in the process induced by cannabinoids (Figure 3c).

Other reports suggest involvement of the MAP/ERK kinase (MEK)-1/-2 pathway in vacuolation. ${ }^{21,24}$ Therefore, we investigated whether specific inhibitors of MEK-1 and -2 influenced the fate of Granta519 cells treated with WIN55,212-2. However, the MEK-1- and -2-specific inhi- bitors, PD98059 and U0126, respectively, were ineffective in protecting from cell death (Figure $3 d$ ).

Cannabinoid-mediated decrease of Granta519 cell viability occurs in a cannabinoid receptor-independent manner and requires active protein synthesis. To verify whether the decrease in Granta519 viability is mediated via CB1 and CB2, we pretreated cells with SR141716 and SR144528, selective antagonists for CB1 and CB2, respectively. Cells were pretreated with 10 or $100 \mathrm{nM}$ of SR141716 and SR144528 for 30 min and then treated with a range of concentrations of WIN55,212-2. Neither SR141716, SR144528 nor a combination of both antagonists inhibited WIN55,212-2-induced cell death or LC3 II lipidation (Figures $4 \mathrm{a}$ and b). Altogether, these findings suggest that the cannabinoid-mediated decrease in Granta519 viability and LC3 II-positive vacuolation are not mediated by CB1 and/or CB2 activation. 
a

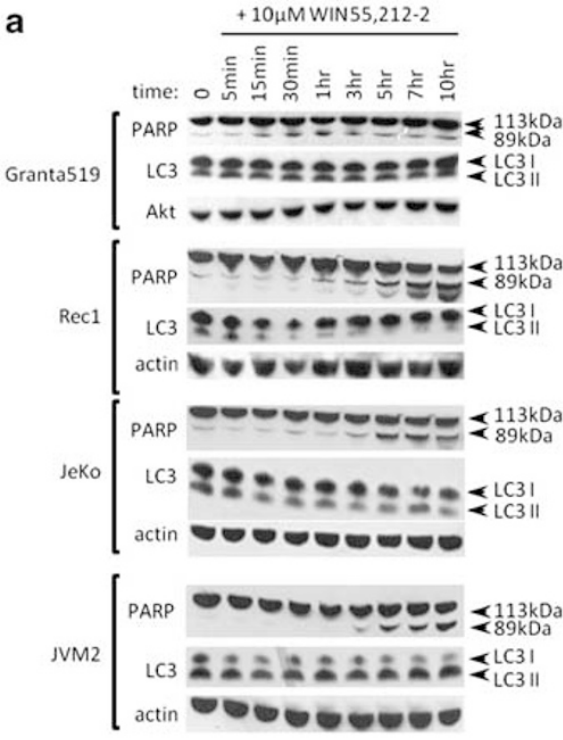

$+10 \mu \mathrm{M}$ WIN $55,212-2$

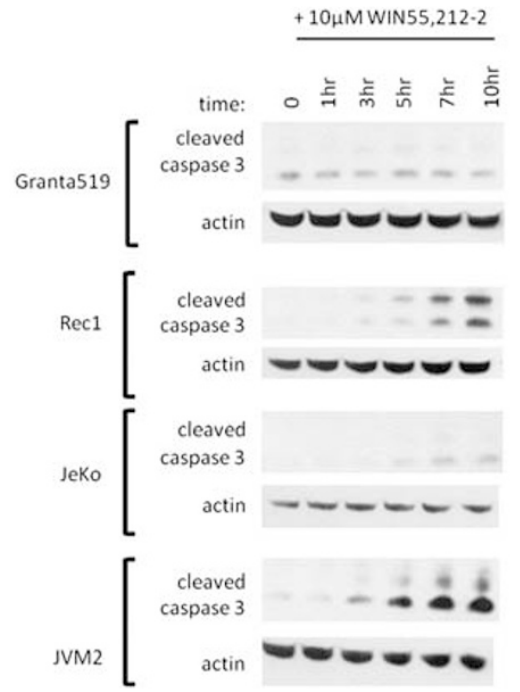

b
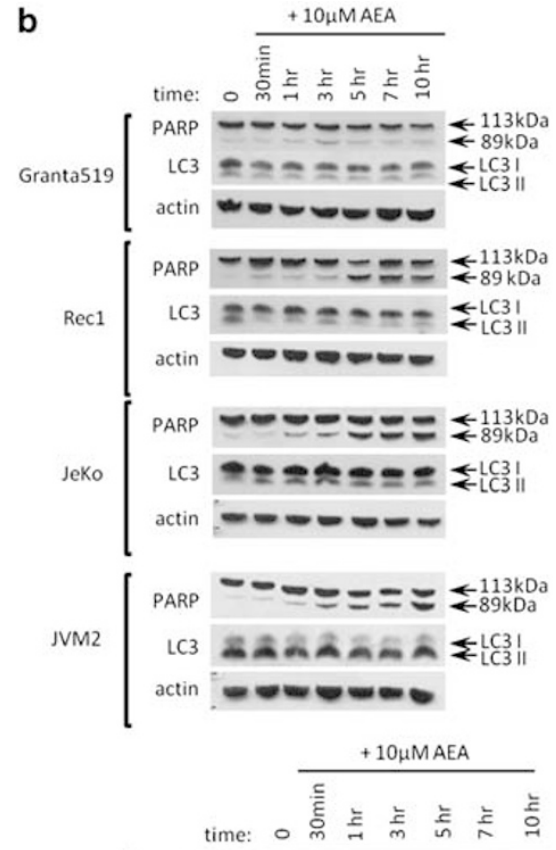

Granta519

cleaved

caspase 3
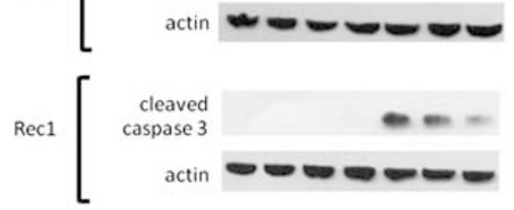

C

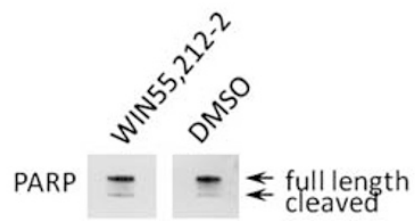

Figure $2 \mathrm{MCL}$ cell lines have variable response to WIN55,212-2 and AEA. MCL cell lines were incubated with cannabinoids and harvested at different time points. After $5 \mathrm{~h}, 10 \mu \mathrm{M}$ WIN55,212-2 (a) or $10 \mu \mathrm{M}$ AEA (b) causes PARP cleavage (full length $=113 \mathrm{kDa}$, cleaved form $=89 \mathrm{kDa}$ ) and caspase-3 cleavage $(19 \mathrm{kDa}$ and $17 \mathrm{kDa})$ in Rec1, JeKo and JVM2 cells, but not in Granta519 cells. Cannabinoids did not affect levels of LC3 II in MCL cell lines up to $10 \mathrm{~h}$ of incubation, $n=2 ; \beta$-actin or Akt were used as a loading control. (c) Expression of PARP in patient PB1 cells treated with $10 \mu \mathrm{M}$ WIN55,212-2 for $24 \mathrm{~h}$

To study whether the cannabinoid-induced cell death is reversible after washing cells off WIN55,212-2, we incubated Granta519 and Rec 1 cells with $10 \mu \mathrm{M}$ WIN55,212-2 for 3 or $6 \mathrm{~h}$ before washing off the drug. The cells were then cultured for another $48 \mathrm{~h}$. Our results show that the decrease in metabolic activity, measured by XTT, was significantly reversed by removing the drug both in Granta519 and Rec1 cells (Figure 5a). For Granta519 cells, washing off the drug also diminished LC3 II positivity (Figure 5a). We then studied the effect of longer exposure of WIN55,212-2 on Granta519 cells. For this, we cultured Granta519 with WIN55,212-2 for $24 \mathrm{~h}$, then washed cells and recultured for another $24 \mathrm{~h}$. Then the decrease in metabolic activity could be significantly reversed (Figure 5b).

We further studied whether the decrease in cell viability and induction of vacuolation require active protein synthesis.
For this, we blocked the biosynthesis of new proteins with cycloheximide (CHX) and then treated Granta519 cells with WIN55,212-2. The addition of CHX significantly protected cells from WIN55,212-2-induced cell death (Figure 5c), implying the requirement of protein biosynthesis.

Vacuoles in cannabinoid-treated Granta519 cells are of ER origin. Light and transmission electron microscopy (TEM) analysis of Granta519 cells at different time points after treatment with $10 \mu \mathrm{M}$ WIN55,212-2 was used to further characterize the vacuole formation. Cells incubated with WIN55,212-2 for $24 \mathrm{~h}$ showed large cytoplasmic vacuoles, whereas the plasma membrane was unaffected. We also observed that the nuclei were intact and noted the occasional appearance of mitotic figures (Figure 6a), whereas vehicletreated Granta519 cells retained a normal ultrastructural 
a

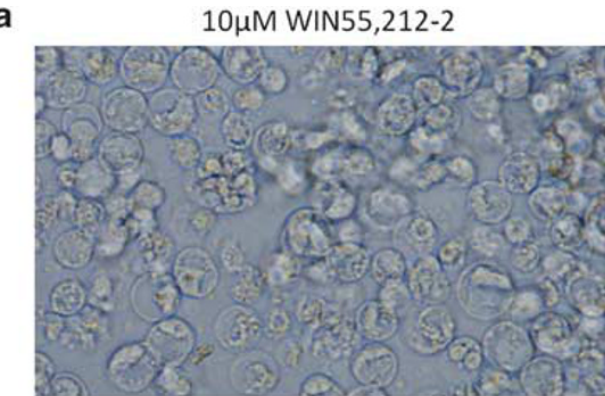

b

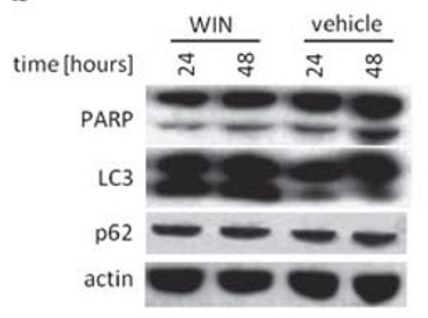

d

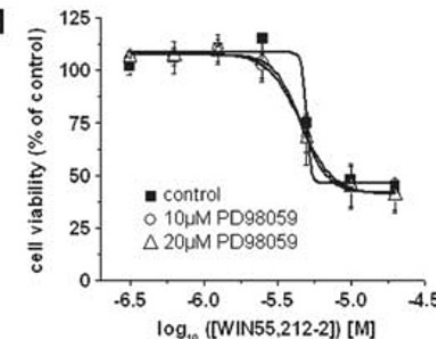

vehicle
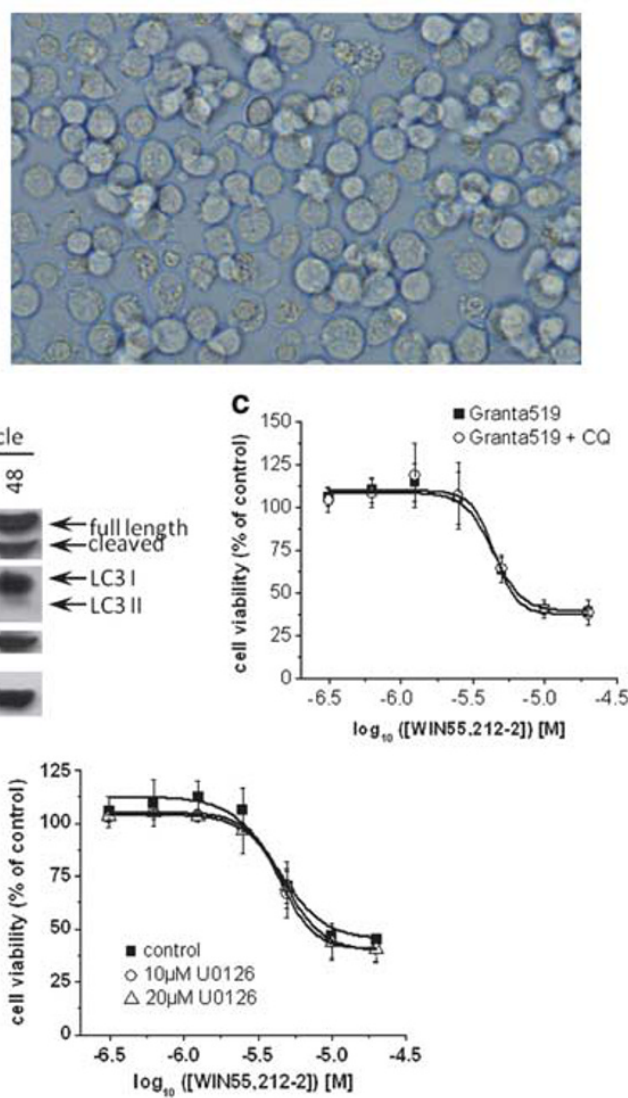

Figure 3 Induction of LC3 II in Granta519 cells in response to WIN55,212-2. (a) Light microscopy images showing cellular morphology of Granta519 cells undergoing cytoplasmic vacuolation after treatment with $10 \mu \mathrm{M}$ WIN55,212-2 for $48 \mathrm{~h}(n=3$, one representative experiment is shown), digital magnification: $\times 40$. (b) WB for PARP, LC3, p62 and $\beta$-actin in Granta519 cells treated with $10 \mu \mathrm{M}$ WIN55,212-2 or AEA or vehicle for 24 and $48 \mathrm{~h}$. Cell viability, measured by XTT assay $(n=3 \times 3)$, of Granta519, pretreated with (c) $25 \mu \mathrm{M} \mathrm{CQ}$, (d) PD98059 or U0126 at indicated concentrations for 30 min before WIN55,212-2 treatment

a

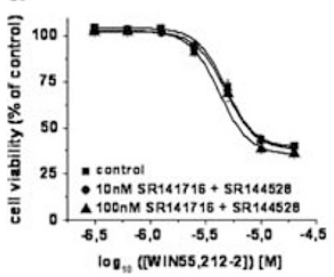

b

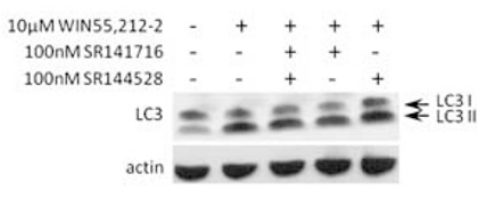

Figure 4 Effect of CB1 and CB2 antagonists on WIN55,212-2-induced cell membrane integrity and LC3 II formation. (a) Granta519 cell were pretreated with SR141716 (antagonist to CB1) and SR144528 (antagonist to CB2) for $30 \mathrm{~min}$ before incubation with increasing concentrations of WIN55,212-2 for $48 \mathrm{~h}$. Cell viability was measured by PI uptake analyzed by flow cytometry. (b) Western blot shows LC3 I and LC3 II expression in Granta519 cells pretreated with SR141716 and /or SR144528 for $30 \mathrm{~min}$ before $24 \mathrm{~h}$ incubation with $10 \mu \mathrm{M}$ WIN55,212-2

morphology, with well defined nuclei containing uniformly distributed chromatin and well preserved organelles (Figures 6 bi and ii). In Granta519 cells treated with $10 \mu \mathrm{M}$ WIN55, 212-2, small amounts of vacuoles in the cytoplasm were seen already at $2 \mathrm{~h}$ of incubation, which increased in number and size with time (Figures 6biii-viii). The vacuoles were surrounded by membranes and some of these membranes were decorated by ribosomes (Figure 6biv), indicating that the intracellular vacuoles were derived from the rough endoplasmic reticulum (ER) and possibly also smooth ER. Most mitochondria remained unchanged up to $6-12 \mathrm{~h}$ of WIN55,212-2 treatment. Then, we observed dilation of the cristae membranes and denser mitochondria matrix. However, in some cells the mitochondrial morphology remained normal even after $24 \mathrm{~h}$ of treatment.

The nuclear membrane was also affected, displaying a widening of the membrane space but with intact nuclear pore complexes (Figure 6bvi). Notably, the outer plasma membranes were not affected, and the general cell morphology did not display any pronounced signs of apoptosis or necrosis. Furthermore, the vacuoles were often empty, but membrane structures could occasionally be found (Figure 6bv).

Immunofluorescence staining showed altered distribution of the ER chaperone calreticulin (Figure 6c). The ER formed large vacuoles in WIN55,212-2-treated cells, confirming that the empty vacuoles within the cytoplasm are indeed of ER origin.

Similar vacuoles, although smaller in size, were formed in PB1 primary cells treated with WIN55,212-2 (Figures 7aiii and iv) compared with PB1 treated with vehicle (Figures 7ai and ii) for $24 \mathrm{~h}$. The smaller size of the vacuoles in primary cells might be 
a

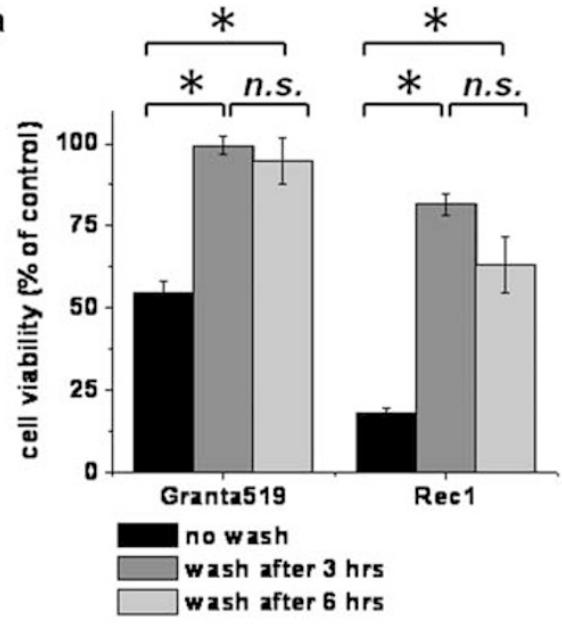

b

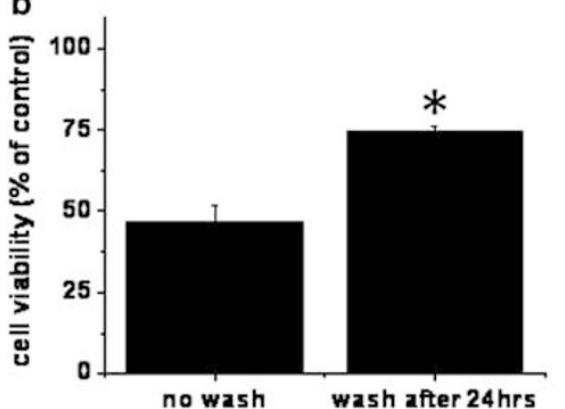

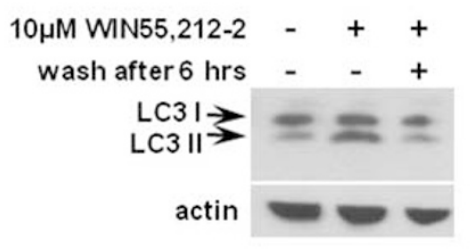

c

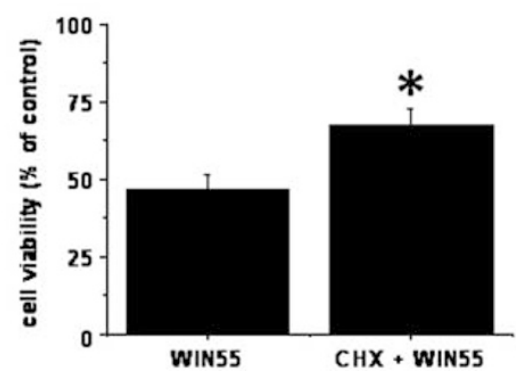

Figure 5 Washing off WIN55,212-2 or treatment with CHX protect Granta519 from WIN55,212-2-induced cytoplasmic vacuolation and cell death. (a) Cell viability of Granta519 and Rec 1 cells incubated with $10 \mu \mathrm{M}$ WIN55,212-2 for 3 and $6 \mathrm{~h}$ before washing off the drug. Then cells were incubated for $48 \mathrm{~h}$, and cell viability was measured by XTT $(P<0.05)$. WB of Granta519 shows decreased LC3 lipidation by washing off $10 \mu \mathrm{M}$ WIN55,212-2 after $6 \mathrm{~h}$. (b) Cell viability (XTT) of Granta519 cells incubated with $10 \mu \mathrm{M}$ WIN55,212-2 for $24 \mathrm{~h}$, followed by washing off the drug and reculturing for $24 \mathrm{~h}(P<0.05)$. (c) $\mathrm{CHX}$ protects from WIN55,212-2-induced cell death measured by XTT; *indicates statistical significance $(P<0.05)$

due to the fact that lymphoma cells ex vivo do not proliferate and the vacuolation process requires new protein synthesis. XTT assay on PB1 cells treated with WIN55,212-2 for $48 \mathrm{~h}$ did not show any changes in mitochondrial activity upon treatment (Figure 7b).

WIN55,212-2 induces ER stress in MCL. The morphological changes of ER in WIN55,212-2-treated Granta519 and PB1 cells prompted further investigation on expression of ER stress-associated proteins: the ER chaperone binding immunoglobulin protein $(\mathrm{BiP})$ that binds to the misfolded proteins and helps them to refold properly and the transcription factor C/EBP (CCAAT/enhancer-binding protein) homologous protein (CHOP) that participates in the pro-apoptotic pathway of the unfolded protein response (UPR). The analysis of $\mathrm{BiP}$ and $\mathrm{CHOP}$ by western blot revealed that WIN55,212-2 treatment upregulates $\mathrm{BiP}$ and $\mathrm{CHOP}$ proteins in all MCL cell lines studied up to $10 \mathrm{~h}$ of treatment with WIN55,212-2 (Figure 8a). This suggests that WIN55,212-2 activates ER stress in MCL cells, but as this response is similar in all investigated cell lines, the ER stress does not discriminate between LC3-II-positive vacuolation or apoptotic cell death. The levels of BiP and CHOP in Granta519 cells remained high also after 24 and $48 \mathrm{~h}$ of treatment (Figure 8b).

\section{Discussion}

We have previously shown that exposure of MCL cells to cannabinoids may induce PCD in vitro and tumor growth reduction in an in vivo xenograft model of $\mathrm{MCL}$. In most instances, apoptosis is the mode of cell death. However, in this report we show that other PCD mechanisms may also induce cell death in MCLs, widening the potential therapeutic usefulness of cannabinoids. The death pathway described in this report was seen both in primary MCLs from two tissues of one patient as well as in the MCL cell line Granta519. The MCL cells that are resistant to cannabinoid-induced apoptotic cell death die via cytoplasmic vacuolation upon cannabinoid treatment. The similar formation of vacuoles, although more pronounced in the Granta519 cell line compared with primary MCL cells, indicates that the mechanism is not a phenomenon of in vitro cultured cells alone, but may be relevant to primary tumor cells.

Salazar et al. ${ }^{25}$ showed that cannabinoids, apart from PCD I (apoptosis), can also induce PCD II (autophagy), followed by caspase-3-dependent apoptosis in glioma, astrocytoma, pancreatic cancer, breast cancer and hepatoma cells. However the response in MCLs is different from that described in Salazar et al., ${ }^{25}$ as we did not find any convincing evidence for autophagy. As Granta519 cells treated with 
a

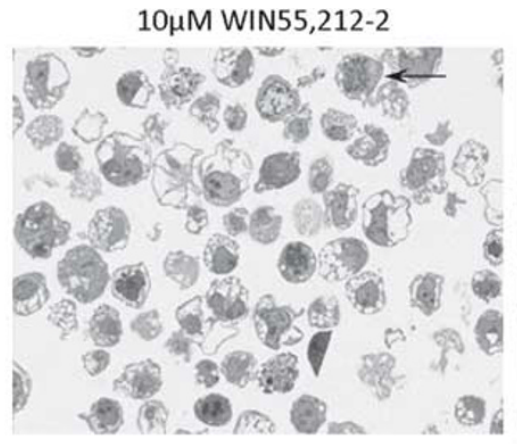

b
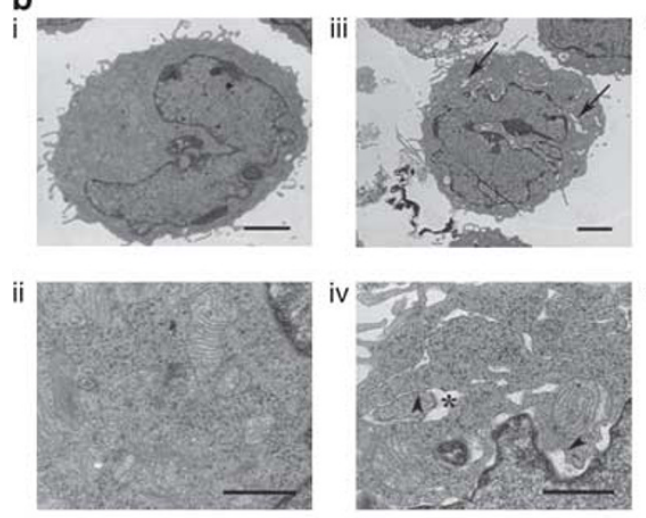

c

$10 \mu \mathrm{M}$ WIN55,212-2
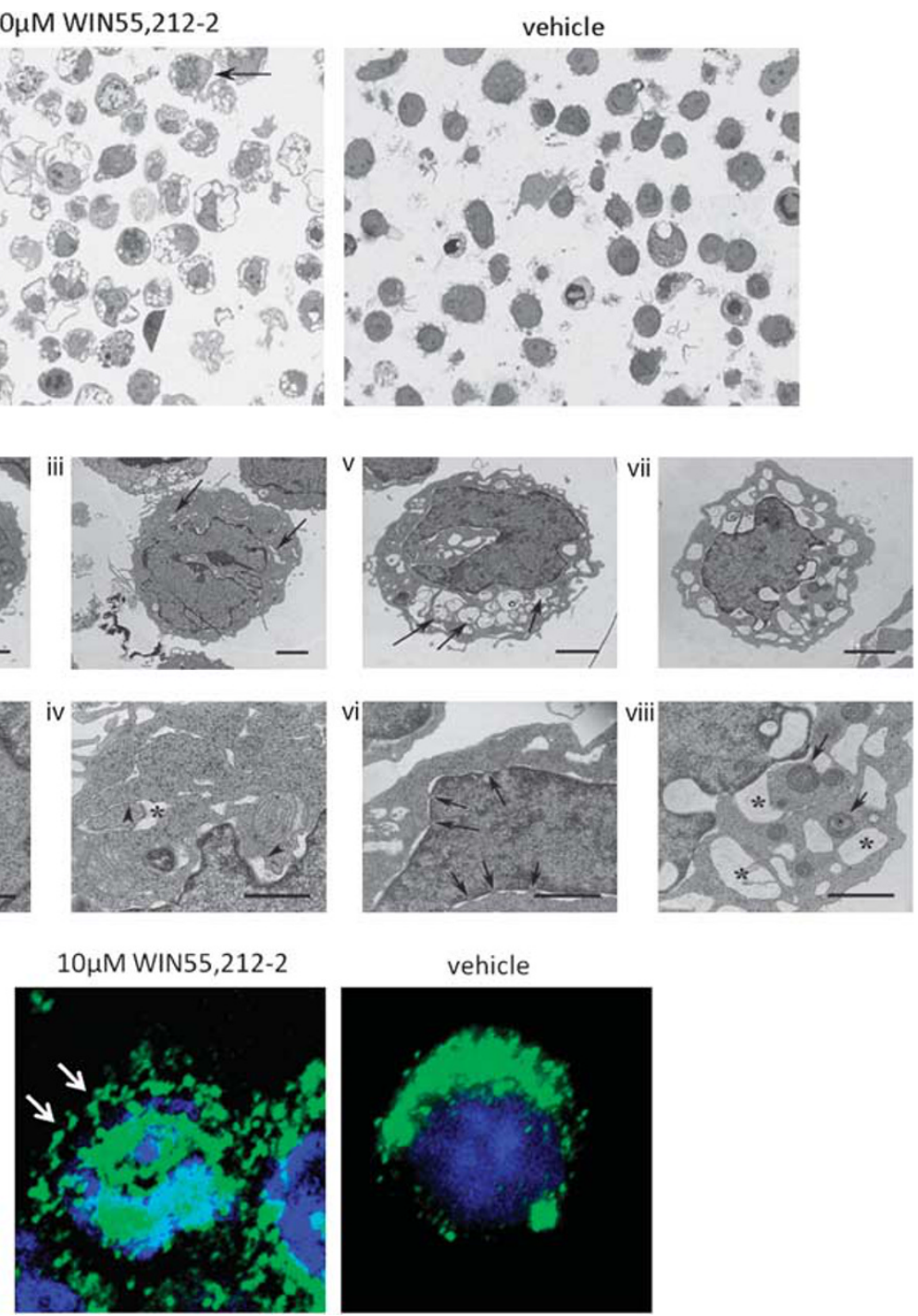

Figure 6 Granta519 cells form vacuoles in response to WIN55,212-2 treatment. (a) Light microscopy pictures of $0.5 \mu \mathrm{m}$ sections prepared as for TEM of Granta519 cells treated with $10 \mu \mathrm{M}$ WIN55,212-2 or vehicle for $24 \mathrm{~h}$. Note the large cytoplasmic vacuoles. Occasional mitotic figures were also detected (black arrow); (b) TEM images of Granta519 cells treated with $10 \mu \mathrm{M}$ WIN55,212-2. Photographs showed cells at different time points after 0 (i and ii); 2 (iii, iv); 6 ( $v$ and vi) and 24 (vii and viii) $h$ of incubation. Normal ultrastructure morphology was predominately found in the control cells $(0 \mathrm{~h})$, showing a well-defined plasma membrane and uniformly distributed chromatin in the nucleus (i) and well-defined organelles in the cytoplasm (ii). After $2 \mathrm{~h}$ of WIN55,212-2 treatment, the cell cytoplasm displayed vacuoles with well-defined membranes (arrows; iii). Ribosomes (arrowheads) are attached to some of these membranes, indicating that these vacuoles ( $\left.{ }^{*}\right)$ were derived from the rough ER (iv). After $6 \mathrm{~h}$, the number and size of these vacuoles increased and some contained membrane structures (arrows; v). The nuclear membrane was also affected, but the nuclear pore complexes were not disrupted (arrows; vi). At $24 \mathrm{~h}$, more necrosis were found and the cells contained more vacuoles (vii). The vacuoles were mostly empty ( ${ }^{*}$ ), and mitochondria were often found in the cytoplasm (viii). Bars: i, iii, v and vii $=2 \mu \mathrm{m}$; ii, iv, vi and viii $=1 \mu \mathrm{m}$. (c) Fluorescence images of Granta519 cells incubated with vehicle or $10 \mu \mathrm{M}$ WIN55,212-2 for $24 \mathrm{~h}$ immunostained for calreticulin (green) and DAPI (blue). White arrows indicate vacuoles surrounded by calreticulin

vehicle for $48 \mathrm{~h}$ showed enhanced PARP cleavage compared with cannabinoid-treated cells (Figure $3 b$ ), it could be hypothesized that cannabinoids induced autophagy to promote survival of starved cells, as all experiments were performed in medium with low serum content. However, the lack of enhanced autophagosome formation observed in TEM micrographs and the lack of lysosomal contribution did not confirm this hypothesis.

Instead, the cannabinoid-induced vacuolation in Granta519 cells associated with decreased metabolism and formation of LC3-II-positive non-autophagic vacuoles are similar to previous descriptions in colon, breast and prostate cancer cell lines treated with the prostaglandin derivative $15 \mathrm{~d}-\mathrm{PGJ} 2 .^{21}$ These features resemble another type of PCD, called paraptosis (from the Greek words para (alongside of, abnormal) and apoptosis). It is characterized by the appearance of large vacuoles of $\mathrm{ER}$ and mitochondrial origin, $^{26}$ and has been denoted as PCD III. Paraptosis, in contrast to apoptosis, does not show activation of the caspase-3 cascade, followed by chromatin condensation nor other apoptotic features. ${ }^{27}$ Paraptosis has no specific definition as yet, and several types of paraptosis-like cell deaths have been described. The first description of PCD by cytoplasmic vacuolation, thus being a 'golden standard', 
a
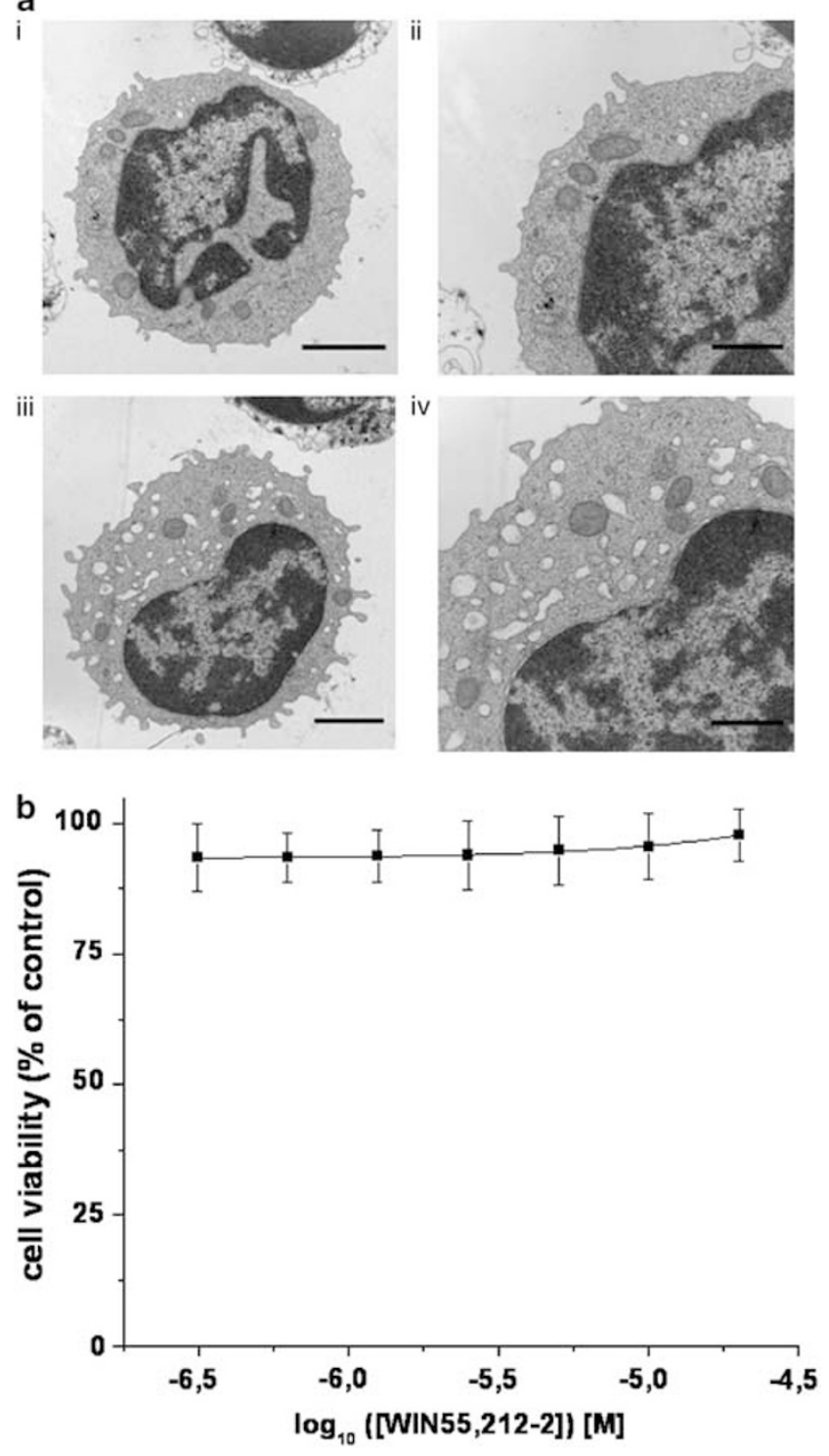

Figure 7 WIN55,212-2 induced vacuolation in PB1 cells. (a) Normal ultrastructure morphology of primary PB1 cells was predominately found in cells treated with the vehicle for $24 \mathrm{~h}$. These cells had a well-defined plasma membrane and uniformly distributed chromatin in the nucleus and well-defined organelles in the cytoplasm ( $\mathrm{i}$ and ii). Cells treated with WIN55,212-2 for $24 \mathrm{~h}$ displayed vacuoles in the cytoplasm. Bars; i and iii $=2 \mu \mathrm{m}$; ii and iv $=1 \mu \mathrm{m}$. (b) PB1 cell viability (XTT) in response to WIN55,212-2 for $48 \mathrm{~h}$. The experiment was performed once in triplicates

was triggered by the overexpression of insulin-like growth factor-1 receptor (IGF1R) in 293T, HEK293, MCF-7 and Cos-7 cells. ${ }^{26}$ Since then the list of cytoplasmic vacuolation inducers has been accumulating, allowing the description of and distinguishing different types of paraptosis-like cell death. For example, epidermal growth factor (EGF)-induced paraptosis differs by induction of simultaneous caspase-independent DNA fragmentation. ${ }^{28}$ IGF1R-induced paraptosis showed to be mediated by the MAPK cascade and sensitive to the MEK-2 inhibitor U0126. ${ }^{24}$ 15d-PGJ2-induced paraptosis is mediated by both the MEK-1 and -2 cascades. ${ }^{21}$ We investigated whether the cannabinoid-induced

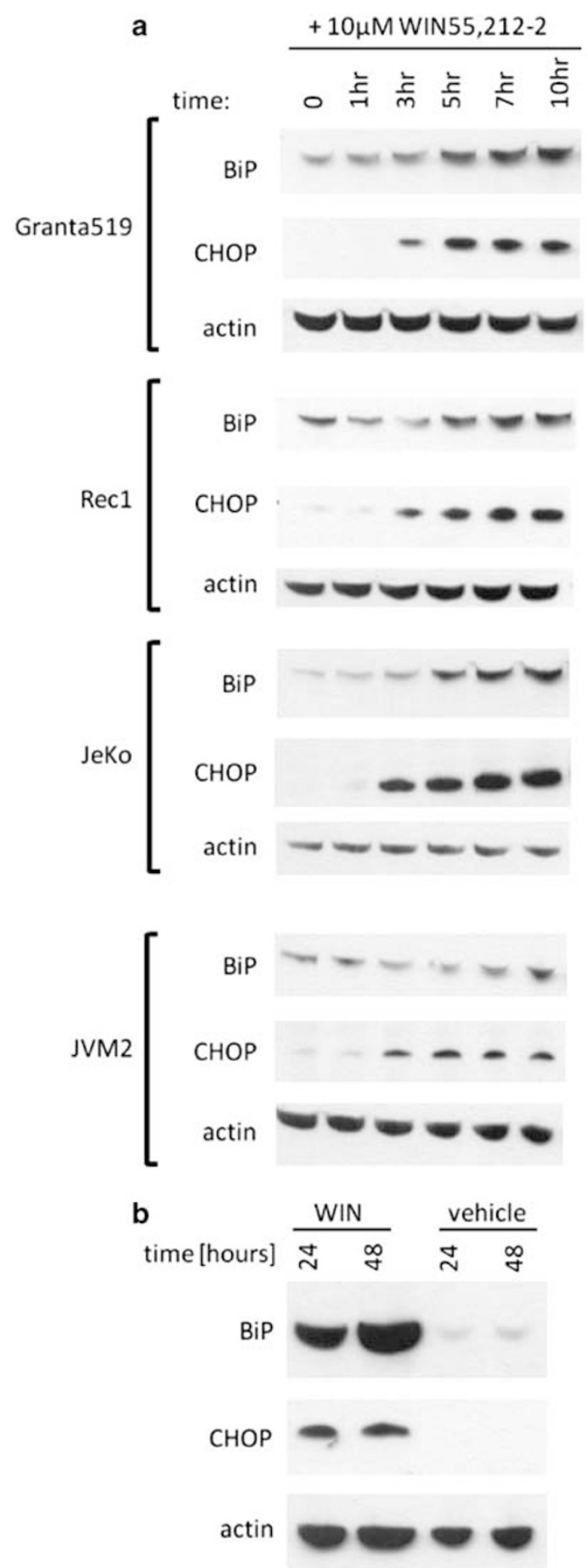

Figure 8 Expression of ER stress markers in MCL cell lines treated with $10 \mu \mathrm{M}$ WIN55,212-2. (a) Western blots depicting expression levels of proteins, BiP, CHOP and $\beta$-actin, in Granta519, Rec1, JeKo and JVM2 cell lines treated with $10 \mu \mathrm{M}$ WIN55,212-2 in a time-course experiment. (b) Expression of BiP, CHOP and actin in Granta519 cells treated with $10 \mu \mathrm{M}$ WIN55,212-2 or vehicle for 24 and $48 \mathrm{~h}$

vacuolation in Granta519 was inhibited by MEK-1 and -2 inhibitors. Similarly to the taxol-induced vacuolation in the ASTC lung adenocarcinoma cell line and the EGF-induced vacuolation in the $\mathrm{GH} 4 \mathrm{C} 1$ rat somatolactotrope cell line, the MEK-2 inhibitor U0126 did not block cannabinoid-induced cell 
death in Granta519. Furthermore, even though both cannabinoids and taxol induce vacuolation of ER origin, the cannabinoid-induced vacuolation, in contrast to the taxolinduced vacuolation, ${ }^{29,30}$ requires active protein synthesis. This is similar to $\mathrm{CHX}$-sensitive vacuolation induced by IGF1R ${ }^{26}$ and $15 d-P G J 2 .{ }^{21}$ Although the cannabinoid-induced vacuolation has many features in common with other paraptosis-like types of cell death, there are also features that are different from paraptosis induced by prostaglandin derivatives, IGF1R overexpression and taxol.

Previously, we have shown that caspase-3 activation in MCL cell lines treated with cannabinoids can be inhibited by cell treatment with selective $\mathrm{CB} 1$ and $\mathrm{CB} 2$ antagonists, SR141716 and SR144528, respectively. Here, we show that neither of these antagonists inhibits WIN55,212-2-induced cell death or LC3 II formation in Granta519. This suggests that the paraptotic cell death occurs independent of cannabinoid receptor signaling. Similar findings have been reported in studies on the prostaglandin derivative, 15d-PGJ2, that activates paraptosis independent of its target receptor, peroxisome proliferator-activated receptor- $\gamma .{ }^{21}$ We also report that WIN55,212-2-induced cell death of Granta519 and Rec1, representing cell lines undergoing paraptosis and apoptosis, respectively, needs constant presence of the cell death stimulus to complete the cell death program. This suggests that cannabinoid-induced cell death may be finely tuned and controlled by repetitive administration of the drug.

TEM and immunofluorescence staining of calreticulin suggest that the vacuoles observed in Granta519 and PB cells treated with WIN55,212-2 are of ER origin. We also observe changes in morphology of mitochondria. These changes occur later (6-12 $\mathrm{h}$ post treatment) than vacuoles and probably are a secondary effect, as cells by this time point show a dramatic change in the morphology.

Cannabinoids can signal for cell death in various types of cancer cells, including MCL, via ceramide de novo synthesis ${ }^{18,20,31}$ occurring in the ER. ${ }^{32}$ Both pharmacological and genetic inhibition of the key enzymes participating in biosynthesis of ceramide abrogated cell death of cannabinoidtreated Rec1 cells. ${ }^{33}$ Accumulation of newly synthesized ceramides in ER can cause ER stress, as reported by Salazar et al. $^{25}$ in THC-treated glioma cells. We now show that the levels of the ER stress proteins, BiP and CHOP, increase in MCL cell lines during $10 \mathrm{~h}$ of incubation with WIN55,212-2. In Granta519, BiP and CHOP remain elevated at 24 and $48 \mathrm{~h}$, respectively, thus at a time point when the process of LC3-IIpositive cytoplasmic vacuolation is extensive. This is in line with other reports showing that cannabinoids activate ER stress. $^{25,34}$ Importantly, ER stress has been also associated with the paraptotic cell death. ${ }^{21,35}$ The fact that cannabinoids induce ER stress in all MCL cell lines studied suggests that the cell decision on entering apoptotic or paraptotic signaling pathway happen after or independent of pro-death UPR signaling. Extensive ER dilation can relate to malfunctioning downstream of apoptotic pathways due to drug effects or genetic alterations in cancer cells. Tardito et al. showed that the copper complex $\mathrm{AO}^{35}$ and other copper complexes, ${ }^{36}$ as well as activating UPR, inhibit caspase-3, probably by direct interactions of copper with the catalytic cysteine in the active site of caspase-3. Moreover, Ding et al. ${ }^{37}$ proposed that proteasome inhibitor MG132 leads to post-UPR ER dilation in $\mathrm{Bcl} 2$-associated $\mathrm{X}$ protein (Bax)-negative as opposed to Bax-positive HCT116 cells.

The molecular bases for these different PCD responses to cannabinoids are yet unknown. Possibly, the balances between pro- and anti-apoptotic factors, such as B-cell lymphoma 2 (Bcl2) family molecules, are divergent between MCLs that are sensitive to cannabinoid-inducing apoptosis and those that undergo paraptosis. Overexpression of $B C L 2$ is not an uncommon event in malignant lymphomas, including MCL, and may be a result of genomic aberrations encompassing the BCL2 locus at chromosome 18q21. In contrast to Rec1, Granta519 carries increased copy numbers of BCL2 and expresses higher BCL2 mRNA levels. ${ }^{38}$ We cannot exclude the possibility that increased expression of $B C L 2$ contributed to the resistance to cannabinoid-induced apoptosis in Granta519. However, JeKo has a near-triploid karyotype, and $\mathrm{CGH}$ analysis has demonstrated an extra copy of $B C L 2$ in this cell line. ${ }^{39}$ Furthermore, Sperandio et al. ${ }^{26}$ showed that, among other inhibitors of apoptosis, a prosurvival member of Bcl2 family, B-cell lymphoma-extra large (Bcl- $\mathrm{x}_{\mathrm{L}}$ ), did not protect 293T-IGFR-IC cells from paraptotic cell death, indicating that proteins outside of anti-apoptotic $\mathrm{Bcl} 2$ family members may be of greater importance. Chen et al. $^{40}$ recently showed that Granta519 cells respond differently to an inhibitor of cyclin-dependent kinases 2, 7 and 9, SNS-032, than other MCL cell lines tested. The authors speculated that Epstein-Barr virus (EBV) positivity as well as $\mathrm{Bcl} 2$ overexpression could contribute to the altered response of Granta519 cell line to SNS-032. ${ }^{40}$ However, the EBVpositive JVM2 cell line underwent apoptosis when treated with cannabinoids. Furthermore, the primary $\mathrm{MCL}$ cells from patient PB were EBER (EBV-encoded RNA) negative (data not shown).

We conclude that cannabinoids may induce cell death by a pathway associated with cytoplasmic vacuolation in cases of MCLs that are resistant to apoptosis. Activation of more than one type of cell death by cannabinoids widens their potential therapeutic usefulness toward lymphomas overexpressing cannabinoid receptors.

\section{Materials and Methods}

Reagents. WIN55,212-2 and AEA were from Tocris (Bristol, UK). CQ, CHX and PI were from Sigma-Aldrich (Dorset, UK). PD98059 and U0126 were from Calbiochem (Merck, Darmstadt, Germany). SR141716 and SR144528 were from Cayman Chemical (Ann Arbor, MI, USA).

Patient samples. Tumour cells were isolated as described previously, ${ }^{20}$ viability frozen in freezing medium containing $10 \%$ DMSO (Merck, Darmstadt, Germany), $40 \%$ fetal bovine serum (FBS; Invitrogen, Paisley, UK) and $50 \%$ $\mathrm{RPMI}+$ GlutaMax (Invitrogen) according to the Biobank procedures at Karolinska University Hospital, Huddinge, and stored at $-135^{\circ} \mathrm{C}$

Cell culture of primary cells and cell lines. Granta519, Rec1, JeKo, JVM2 cell lines and primary cells were obtained and cultured as previously described. ${ }^{4}$ Before setting up experiments, cells were cultured for $4 \mathrm{~h}$ (primary cells) or overnight (cell lines) in RPMI + GlutaMax (Invitrogen) with 1\% FBS (Invitrogen). It is common to use $1 \%$ serum in media when performing experiments with cannabinoids, as many cannabinoids bind to serum components (for a review, see Flygare and Sander ${ }^{18}$ ). 
Cell viability. Viability was assessed by (1) the XTT assay (measuring the (primarily) mitochondrial, metabolic activity) according to the manufacturer's instructions (Roche, Mannheim, Germany) or by (2) flow cytometric analysis (FACSCalibur, BD Biosciences, Bedford, MA, USA) of PI (Sigma-Aldrich; final concentration $1 \mu \mathrm{g} / \mathrm{ml}$ ) uptake by cells lacking plasma membrane integrity. Results were analyzed using FlowJo 7 (Tree Star Inc., Ashland, OR, USA) for Windows, and pharmacological interpretation was done using a four-parameter logistic equation with iterative fitting (dose-response fitting) using OriginPro 8 (OriginLab, Northampton, MA, USA).

Western blotting. Cells were pelleted and frozen at $-20^{\circ} \mathrm{C}$ or used immediately after pelleting for preparing cell lysates using RIPA buffer (SigmaAldrich) supplemented with protease inhibitor cocktail (Sigma-Aldrich). Proteins were separated on $12 \%$ NuPAGE gels from Invitrogen and then transferred using semidry transfer system onto PVDF membrane (Millipore, Solna, Sweden). Membranes were blocked with $10 \%$ dry milk in TBS solution for $2 \mathrm{~h}$ at room temperature (RT) and then probed overnight at $4{ }^{\circ} \mathrm{C}$ or for $2 \mathrm{~h}$ at RT with primary antibodies: anti-PARP, anti-caspase-3, anti-LC3, anti-BiP or anti-Akt (Cell Signaling, Danvers, MA, USA) or anti-p62, anti- $\beta$-actin (Sigma-Aldrich) in $5 \%$ dry milk or $5 \%$ BSA for anti-CHOP (Cell Signaling) in TBS. Membranes were then washed in TBS and probed with secondary antibodies (anti-rabbit or anti-mouse; GE Healthcare Bio-Sciences Corp., Uppsala, Sweden). Blots were developed using Supersignal West Pico (Pierce, Biotechnology, Shelton, CT, USA) and wet-developing method (developer and fixer solutions were from Kodak (SigmaAldrich) and films were from GE Healthcare). For reprobing membranes, HRP was blocked using the SG substrate kit (Vector Labs, Peterborough, UK).

RNA isolation and cDNA synthesis. RNA was isolated using the RNeasy Plus mini kit (Qiagen, Sollentuna, Sweden) according to the manufacturer's protocol. Quantification and quality of the RNA preparations were measured using the NanoDrop ND-1000 spectrophotometer (Saveen Werner, Stockholm, Sweden). Complementary DNA (cDNA) was synthesized using the Omniscript Reverse Transcription kit (Qiagen) according to manufacturer's protocol. RNaseOut recombinant ribonuclease inhibitor and the oligo dT primers used were purchased from Invitrogen.

Quantitative PCR. mRNA expression levels of CNR1 and CNR2 were assessed by real-time PCR using Platinum SYBR Green qPCR Supermix-UDG (Invitrogen) according to the manufacturer's protocol. Primers sequences (Eurogentec, Seraing, Belgium) for the selected genes were as follows: CNR1 forward: $5^{\prime}$-CATTAAGACGGTGTTTGCATTCT-3' and reverse: $5^{\prime}$-CGTGTCG CAGGTCCTTACTC-3', amplifying 1185-1282 bp (transcript variant 1) and 1018$1115 \mathrm{bp}$ (transcript variant 2). CNR2 primers were $5^{\prime}$-GACACGGACCC CTTTTTGCT-3' (forward primer) and $5^{\prime}$-CCTCGTGGCCCTACCTATCC- ${ }^{\prime}$ (reverse primer), amplifying $1321-1423 \mathrm{bp}$. $\beta$-Actin primers were $5^{\prime}$-AAAGACCT GTACGCCAACACA-3' (forward primer) and 5'-AGTACTTGCGCTCAGGAGGA-3' (reverse primer), amplifying $955-1096 \mathrm{bp}$. Each sample was prepared in triplicates in a 96-well plate (Bio-Rad Laboratories, Sundyberg, Sweden) and the reactions were performed with the $\mathrm{C} 1000$ Thermal cycler (Bio-Rad). An initial step was performed at $95^{\circ} \mathrm{C}$ for $2 \mathrm{~min}$, followed by 40 cycles at $95^{\circ} \mathrm{C}$ for $15 \mathrm{~s}$ and finished by $57^{\circ} \mathrm{C}$ for $30 \mathrm{~s}$. The results were analyzed and cycle threshold $(\mathrm{Ct})$ values of transcripts were quantified using CFX manager software (Bio-Rad). The $\Delta \mathrm{Ct}$ values were calculated using $\beta$-actin as reference. cDNA from buffy coat $\mathrm{B}$ cells was used as control for $C N R 1$ and $C N R 2$ to calculate the $\Delta \Delta C$ t value and to determine the relative fold increase.

Immunofluorescence microscopy. Cells were grown on poly-L-lysinecoated coverslips, then spun down, washed and incubated with 4\% PFA at RT. After washing, cells were incubated with primary mouse anti-calreticulin (Abcam, Cambridge, UK) antibody at $4{ }^{\circ} \mathrm{C}$ overnight. After washing secondary anti-mouse, Alexa488-conjugated antibody was applied for $1 \mathrm{~h}$ at RT. Cells were washed and mounted onto slide using mounting media with DAPI (Vector Labs). Staining was examined on Leica DM RXA fluorescence microscope (Leica Microsystems, Wetzlar, Germany) using SlideBook 5.0 software (Intelligent Imaging Innovations, Göttingen, Germany). The images were analyzed using software ImageJ for Macintosh (US National Institutes of Health, Bethesda, MD, USA).

Transmission electron microscopy. Cells were fixed in $2.5 \%$ glutaraldehyde in $0.1 \mathrm{M}$ phosphate buffer, $\mathrm{pH} 7.4$, at RT for $30 \mathrm{~min}$. Next, cells were transferred to Eppendorf tubes (Hamburg, Germany) and further fixed overnight in the refrigerator. After fixation, cells were rinsed in $0.1 \mathrm{M}$ phosphate buffer and centrifuged. The pellets were then postfixed in $2 \%$ osmium tetroxide in $0.1 \mathrm{M}$ phosphate buffer, $\mathrm{pH} 7.4$, at $4{ }^{\circ} \mathrm{C}$ for $2 \mathrm{~h}$, dehydrated in ethanol, followed by acetone and embedded in LX-112 (Ladd, Burlington, VT, USA). Sections were contrasted with uranyl acetate, followed by lead citrate and examined in a Tecnai 12 TEM (Fei Company, Eindhoven, The Netherlands) at $80 \mathrm{kV}$. Digital images were taken by using a Veleta camera (Olympus Soft Imaging Solutions, GmbH, Munster, Germany).

Ethical permission. This study was approved by the Ethics Committee at Karolinska Institutet.

\section{Conflict of Interest}

The authors declare no conflict of interest.

Acknowledgements. We are grateful to the personnel at the Flow Cytometry Unit at Karolinska University Hospital Huddinge for help with collection of patient samples and flow cytometry. This study was financially supported by grants from the Swedish Cancer Society, the Swedish Research Council, the Cancer Society in Stockholm, the Karolinska Institutet Funds and the Stockholm County Council.

1. Bertoni F, Ponzoni M. The cellular origin of mantle cell lymphoma. Int $J$ Biochem Cell Biol 2007; 39: 1747-1753.

2. Jares P, Colomer D, Campo E. Genetic and molecular pathogenesis of mantle cell lymphoma: perspectives for new targeted therapeutics. Nat Rev Cancer 2007; 7 : 750-762.

3. Geisler CH, Kolstad A, Laurell A, Andersen NS, Pedersen LB, Jerkeman M et al. Long-term progression-free survival of mantle cell lymphoma after intensive front-line immunochemotherapy with in vivo-purged stem cell rescue: a nonrandomized phase 2 multicenter study by the Nordic Lymphoma Group. Blood 2008; 112: 2687-2693.

4. Gustafsson K, Wang X, Severa D, Eriksson M, Kimby E, Merup M et al. Expression of cannabinoid receptors type 1 and type 2 in non-Hodgkin lymphoma: growth inhibition by receptor activation. Int J Cancer 2008; 123: 1025-1033.

5. Islam TC, Asplund AC, Lindvall JM, Nygren L, Liden J, Kimby E et al. High level of cannabinoid receptor 1 , absence of regulator of $G$ protein signalling 13 and differential expression of cyclin D1 in mantle cell lymphoma. Leukemia 2003; 17: 1880-1890.

6. Bouaboula M, Rinaldi M, Carayon P, Carillon C, Delpech B, Shire D et al. Cannabinoidreceptor expression in human leukocytes. Eur J Biochem 1993; 214: 173-180.

7. Galiegue S, Mary S, Marchand J, Dussossoy D, Carriere D, Carayon P et al. Expression of central and peripheral cannabinoid receptors in human immune tissues and leukocyte subpopulations. Eur J Biochem 1995; 232: 54-61.

8. McKallip RJ, Lombard C, Fisher M, Martin BR, Ryu S, Grant S et al. Targeting CB2 cannabinoid receptors as a novel therapy to treat malignant lymphoblastic disease. Blood 2002; 100: 627-634.

9. Borner C, Hollt V, Kraus J. Activation of human T cells induces upregulation of cannabinoid receptor type 1 transcription. Neuroimmunomodulation 2007; 14: 281-286.

10. Springs AE, Karmaus PW, Crawford RB, Kaplan BL, Kaminski NE. Effects of targeted deletion of cannabinoid receptors $\mathrm{CB} 1$ and $\mathrm{CB} 2$ on immune competence and sensitivity to immune modulation by delta9-tetrahydrocannabinol. J Leukoc Biol 2008; 84: 1574-1584.

11. Klein TW. Cannabinoid-based drugs as anti-inflammatory therapeutics. Nat Rev Immunol 2005; 5: 400-411.

12. Agudelo M, Newton $\mathrm{C}$, Widen $\mathrm{R}$, Sherwood $\mathrm{T}$, Nong L, Friedman $\mathrm{H}$ et al. Cannabinoid receptor 2 (CB2) mediates immunoglobulin class switching from IgM to IgE in cultures of murine-purified B lymphocytes. J Neuroimmune Pharmacol 2008; 3: 35-42.

13. Alberich Jorda M, Rayman N, Tas M, Verbakel SE, Battista N, van Lom K et al. The peripheral cannabinoid receptor $\mathrm{Cb2}$, frequently expressed on AML blasts, either induces a neutrophilic differentiation block or confers abnormal migration properties in a ligand-dependent manner. Blood 2004; 104: 526-534.

14. Ghosh S, Preet A, Groopman JE, Ganju RK. Cannabinoid receptor CB2 modulates the CXCL12/CXCR4-mediated chemotaxis of T lymphocytes. Mol Immunol 2006; 43: 2169-2179.

15. Pereira JP, An J, Xu Y, Huang Y, Cyster JG. Cannabinoid receptor 2 mediates the retention of immature B cells in bone marrow sinusoids. Nat Immunol 2009; 10: 403-411.

16. Bifulco M, Di Marzo V. Targeting the endocannabinoid system in cancer therapy: a call for further research. Nat Med 2002; 8: 547-550.

17. Fowler CJ, Gustafsson SB, Chung SC, Persson E, Jacobsson SO, Bergh A. Targeting the endocannabinoid system for the treatment of cancer-a practical view. Curr Top Med Chem 2010; 10: 814-827.

18. Flygare J, Sander B. The endocannabinoid system in cancer-potential therapeutic target? Semin Cancer Biol 2008; 18: 176-189. 
19. Flygare J, Gustafsson K, Kimby E, Christensson B, Sander B. Cannabinoid recepto ligands mediate growth inhibition and cell death in mantle cell lymphoma. FEBS Lett 2005; 579: 6885-6889.

20. Gustafsson K, Christensson B, Sander B, Flygare J. Cannabinoid receptor-mediated apoptosis induced by $\mathrm{R}(+)$-methanandamide and Win55,212-2 is associated with ceramide accumulation and p38 activation in mantle cell lymphoma. Mol Pharmacol 2006; 70: 1612-1620.

21. Kar R, Singha PK, Venkatachalam MA, Saikumar P. A novel role for MAP1 LC3 in nonautophagic cytoplasmic vacuolation death of cancer cells. Oncogene 2009; 28 : 2556-2568.

22. Klionsky DJ, Abeliovich H, Agostinis P, Agrawal DK, Aliev G, Askew DS et al. Guidelines for the use and interpretation of assays for monitoring autophagy in higher eukaryotes. Autophagy 2008; 4: 151-175.

23. Mizushima N, Yoshimori T, Levine B. Methods in mammalian autophagy research Cell 2010; 140: 313-326.

24. Sperandio S, Poksay K, de Belle I, Lafuente MJ, Liu B, Nasir J et al. Paraptosis: mediation by MAP kinases and inhibition by AIP-1/Alix. Cell Death Differ 2004; 11: 1066-1075.

25. Salazar M, Carracedo A, Salanueva IJ, Hernandez-Tiedra S, Lorente M, Egia A et al Cannabinoid action induces autophagy-mediated cell death through stimulation of ER stress in human glioma cells. J Clin Invest 2009; 119: 1359-1372.

26. Sperandio S, de Belle I, Bredesen DE. An alternative, nonapoptotic form of programmed cell death. Proc Natl Acad Sci U S A 2000; 97: 14376-14381.

27. Kroemer G, Galluzzi L, Vandenabeele P, Abrams J, Alnemri ES, Baehrecke EH et al. Classification of cell death: recommendations of the Nomenclature Committee on Cell Death 2009. Cell Death Differ 2009; 16: 3-11.

28. Fombonne J, Padron L, Enjalbert A, Krantic S, Torriglia A. A novel paraptosis pathway involving LEI/L-DNasell for EGF-induced cell death in somato-lactotrope pituitary cells. Apoptosis 2006; 11: 367-375

29. Chen TS, Wang XP, Sun L, Wang LX, Xing D, Mok M. Taxol induces caspase-independen cytoplasmic vacuolization and cell death through endoplasmic reticulum (ER) swelling in ASTC-a-1 cells. Cancer Lett 2008; 270: 164-172

30. Sun $Q$, Chen $T$, Wang $X$, Wei $X$. Taxol induces paraptosis independent of both protein synthesis and MAPK pathway. J Cell Physiol 2010; 222: 421-432.

31. Guzman M. Cannabinoids: potential anticancer agents. Nat Rev Cancer 2003; 3: 745-755.
32. Ogretmen B, Hannun YA. Biologically active sphingolipids in cancer pathogenesis and treatment. Nat Rev Cancer 2004; 4: 604-616.

33. Gustafsson K, Sander B, Bielawski J, Hannun YA, Flygare J. Potentiation of cannabinoidinduced cytotoxicity in mantle cell lymphoma through modulation of ceramide metabolism. Mol Cancer Res 2009; 7: 1086-1098.

34. Lim MP, Devi LA, Rozenfeld R. Cannabidiol causes activated hepatic stellate cell death through a mechanism of endoplasmic reticulum stress-induced apoptosis. Cell Death Dis 2011; 2: e170.

35. Tardito S, Isella C, Medico E, Marchio L, Bevilacqua E, Hatzoglou M et al. The thioxotriazole copper(II) complex $A 0$ induces endoplasmic reticulum stress and paraptotic death in human cancer cells. J Biol Chem 2009; 284: 24306-24319.

36. Tardito S, Bassanetti I, Bignardi C, Elviri L, Tegoni M, Mucchino $\mathrm{C}$ et al. Copper binding agents acting as copper ionophores lead to caspase inhibition and paraptotic cell death in human cancer cells. J Am Chem Soc 2011; 133: 6235-6242.

37. Ding WX, Ni HM, Yin XM. Absence of Bax switched MG132-induced apoptosis to nonapoptotic cell death that could be suppressed by transcriptional or translational inhibition. Apoptosis 2007; 12: 2233-2244.

38. de Leeuw RJ, Davies JJ, Rosenwald A, Bebb G, Gascoyne RD, Dyer MJ et al. Comprehensive whole genome array $\mathrm{CGH}$ profiling of mantle cell lymphoma model genomes. Hum Mol Genet 2004; 13: 1827-1837.

39. Camps J, Salaverria I, Garcia MJ, Prat E, Bea S, Pole JC et al. Genomic imbalances and patterns of karyotypic variability in mantle-cell lymphoma cell lines. Leuk Res 2006; 30: 923-934.

40. Chen R, Chubb S, Cheng T, Hawtin RE, Gandhi V, Plunkett W. Responses in mantle cell lymphoma cells to SNS-032 depend on the biological context of each cell line. Cancer Res 2010; 70: 6587-6597.

Cell Death and Disease is an open-access journal published by Nature Publishing Group. This work is licensed under the Creative Commons Attribution-Noncommercial-No Derivative Works 3.0 Unported License. To view a copy of this license, visit http://creativecommons.org/licenses/by-nc-nd/3.0/ 